\title{
Martín Kohan y la metaliteratura de la revolución ${ }^{1}$
}

Lucía Feuillet $^{2}$

Resumen: Nuestro artículo aborda las ideas de lectura/escritura en la novela Museo de la Revolución, de Martín Kohan. Allí se construye un vínculo entre tiempos históricos distantes y superpuestos a partir de personajes que seducen y traicionan o transgreden y son descubiertos. Los saltos temporales y la continuidad fragmentaria de la revolución proponen un modo de descifrar la ficción. En el instante de peligro se recupera la voz de los vencidos para evitar la apropiación ilegítima de los significados históricos, pero también para configurar lo literario. La revolución permanente es el concepto que subsume los problemas del relato, la historia y la Historia, como un modo de lectura de la organización discursiva, temporal y social.

Palabras clave: revolución - tiempo - literatura - relaciones sociales
Abstract: Our article approaches the reading/writing ideas in the Martin Kohan novel, Museo de la Revolución. In the mentioned novel, the characters that seduce, betray or transgress and are eventually exposed build a link between both, distant and overlapping historical times. The temporary jumps and the fragmentary continuity of the revolution are proposed as a method to decipher fiction. At a time of immediate danger, the voice of the defeated is recovered to avoid the illegitimate appropriation of historical meanings, as well as to configure literature. The concept that subsumes the problems of the narrative, the story and the history is the continuous revolution, as a way of reading the temporal and social organization.

Keywords: revolution - time - literature social relationships

\section{Introducción}

[Máximo Gorki] Al comentar un congreso de «indigentes rurales» realizado en Moscú en el año 19 señala que «parios cientos de campesinos fueron alojados en el palacio de invierno de los Romanop. Cuando una vez finalizado el congreso estos hombres se marcharon se vio que no

\footnotetext{
1 Trabajo recibido el 17/04/2017. Aceptado el 17/06/2017.

${ }^{2}$ Licenciada en Letras Modernas y doctoranda de la Facultad de Filosofía y Humanidades de la Universidad Nacional de Córdoba. Becaria del Consejo Nacional de Investigaciones Científicas y Técnicas. Contacto: feuilletlucia@gmail.com
} 
sólo todos los baños del palacio, sino una enorme cantidad de jarrones de

Sèvres, de Sajonia y de Oriente habian sido empleados como orinales

[...] este hecho vituperable fue la expresión del deseo de estropear, de deteriorar los objetos bonitos» (M. Gorki: Mis recuerdos de Lenin, $p$. 24). Ni se le pasa por la cabeza pensar que los campesinos actuaban sin saberlo como criticos de arte, es decir, usaban los jarrones de Sèvres [...]

La belleza es intocable: debe ser inuitil. Ahi está todo el crimen: un crimen contra la propiedad.

Ricardo Piglia «Nombre falso» en Nombre falso

Su conocimiento de México y su simpatía por la lucha de los obreros y campesinos contra los imperialistas y hacendados le permitian empenarse en una intima conversación con un obrero que pasaba por la casa o discutir la reforma agraria en los términos más simples con el campesino que encontraba en su paseo. Creia que lo que caracteriza a un revolucionario es su actitud hacia los pueblos coloniales y sus luchas por la emancipación.

Extracto del artículo «Con Trotsky en México» de Charles Cornell. León Trotsky «Apéndice» en Escritos latinoamericanos

Nuestra lectura de la novela de Martín Kohan parte de una paradoja literaria: ¿cómo leer un texto que habla de la/s historia/s de la/s revolución/es o de la teoría marxista en clave literaria? o ¿cómo leer un texto-mosaico de citas de Karl Marx, Friedric Engels, Vladimir I. Lenin y León Trotsky que es a la vez una novela? y, 'cómo se habla de la historia y teoría de la revolución en la literatura? Para comenzar a ensayar una respuesta lo primero que se nos plantea es la cuestión de la técnica que estructura el relato. La novela se configura a la manera de una caja china vocal a destiempo histórico, con voces que componen un complejo discurso diario-ensayístico dentro de la historia: alguien cuenta en primera persona lo que otro lee en el manuscrito inédito de un desaparecido. En este sentido, una posibilidad de abordaje emerge al pensar que Museo de la revolución es más una novela sobre la lectura/escritura que una reflexión ensayística sobre la revolución a partir de la ficción. De esta manera, la teoría marxista sobre la revolución puede ser un instrumento de lectura que ayude a revelar las claves metaliterarias en el texto.

Tres referencias temporales convocan una continuidad metadiscursiva. En 1975, Rubén Tesare, el militante de una organización políti- 
ca cuyo nombre no se indica, lee sus escritos sobre la revolución y el tiempo mientras viaja a un pueblo cordobés a entregar un bolso. El destino final del paquete es Tucumán ${ }^{3}$, «zona boscosa y de combate» ${ }^{4}$, adonde llegaría gracias al encuentro con un compañero que nunca sucede. A su vez, Tesare tiene un cuaderno de notas que habla de las revoluciones rusas (1905-1917) y su tradición construida a partir de Marx y Engels. Este es el eje sobre el que Tesare hace girar toda la discusión sobre el marxismo y su idea del tiempo, subsumido en la perspectiva de la revolución permanente. Por otro lado, en 1995 un editor argentino motivado más por la curiosidad que por el interés comercial se deja seducir por la historia de Tesare y su narradora, Norma Rossi, en un viaje de negocios en territorio mexicano.

Un texto inexistente determina la relación comercial, de lectura y seducción, y porta el saber sobre el enigma a resolverse en la novela. Los diarios de Tesare operan como coartada de la ladrona-delatora-narradora, cuyo saber excede el testimonio del protagonista. Si lo enunciamos en los términos del género policial, podemos decir que, en un segundo nivel, accedemos al relato de la vida del desaparecido mediante la figura de una criminal, de una voz doblemente delictiva, primero, como cómplice de un secuestro ilegal y desaparición y luego como poseedora ilegítima de un texto ajeno. El personaje femenino que seduce a Marcelo tal como hizo veinte años atrás con Tesare, miente sobre la existencia de los diarios para legitimar su versión de la noche del secuestro y ocultar su identidad criminal. Norma se apropia de la perspectiva de Tesare, aunque a veces desliza saberes que exceden el foco del personaje. Por ejemplo, en la escena del viaje a Córdoba, se sabe qué hacen los choferes mientras nuestro protagonista duerme: «Para cuando regresan los dos choferes (uno cuenta que estén todos los pasajeros y el otro pone el micro marcha atrás, Tesare ya duerme $»^{5}$. Por otro lado, en ocasiones Norma deja filtrar su voz a pesar de estar narrando el contenido de un diario ajeno: «Hay que saber desvestir a una mujer, dice Norma, no sé si en su propio nombre o citando el diario de Rubén Tesare» ${ }^{6}$.

\footnotetext{
${ }^{3}$ La narración hace referencia al combate de Machalá, en que el Ejército Revolucionario del Pueblo-ERP se enfrenta al «Operativo Independencia» librado por el gobierno peronista contra un supuesto foco guerrillero.

${ }^{4}$ Kohan, (2012): 49.

${ }^{5}$ Kohan, (2012): 23.

${ }^{6}$ Kohan, (2012): 126.
} 
El armado de voces complejiza el relato que abordamos porque, al igual que la revolución, pareciera replicarse de manera superpuesta en todos los tiempos. La lectura se multiplica obsesivamente, creando un efecto de un sentido de permanencia fragmentaria. Marcelo narra la propia historia con Norma en primera persona, desde la intranquilidad del seducido que no puede dominar la regulación de información en la lectura y se ve controlado por el deseo propio hacia la figura femenina y hacia el texto-relato de vida de Tesare. Empujado por esto, su postura es, por momentos, desideologizante, coherente con un estereotipo muy propio de los noventa. En una escena de recorrido por la ciudad, mira los murales de Diego Rivera en el Palacio de Gobierno como si mirara la tapa de Gente con los personajes del año o una foto con compañeros del secundario $^{7}$. Mientras, para acceder a los diarios de Tesare, escucha con tedio la constante lectura de las notas ensayísticas que no lo motivan hacia ninguna reflexión ideológica.

Sin embargo, su figura como lector se transforma a medida que comienza a involucrarse cada vez más ante la intervención de la narradora, y se pregunta, aunque de manera impotente, sobre la legitimidad del saber de Rossi. Asiste a la lectura a la manera de un escucha por momentos desinteresado, que accede a una historia por curiosidad al principio, la sigue mecánicamente hasta que se ve arrastrado hacia la duda sobre los métodos de administración del saber en el relato. El editor, endeble detective exento de la búsqueda de justicia, no puede hacer nada más que interrogar -en ocasiones tímidamente-, hasta adquirir el carácter y compromiso con el pasado que le permita descifrar el enigma. Finalmente, en la instancia de una conversación telefónica en la que el formato del interrogatorio se cuela con una adivinación del destino de Tesare, Marcelo descubre el engaño al que ha sido sometido.

Además, se superponen los tiempos históricos con el presente narrativo de Tesare, lapsos paralelos en que la experiencia subjetiva se refiere al acontecimiento y la significación histórica se desdibuja en la dominación del puro presente. La imagen del Lenin fatigado el día después de la revolución que refiere Trotsky y recupera Tesare, la brusquedad de la transición de la ilegalidad al poder y la rutina como refugio de esta descoordinación temporal ${ }^{8}$ dan cuenta de esta contradicción. Finalmente, dicha discordancia temporal resignifica la experiencia subjetiva del

\footnotetext{
7 Kohan, (2012): 41.

${ }^{8}$ CFR. Kohan, (2012):188-189.
} 
militante, la rabia por el pedido de la «comisión de control» de su organización -dejar de ver a Gabriela porque es montonera- es lo que lo lleva a ceder ante la presencia desafiante de Fernanda Aguirre-Norma Rossi. Allí, en un pueblo pequeño de Córdoba donde pareciera que la moralidad revolucionaria se suspende, donde el peligro no se percibe, es donde tiene lugar la desenvuelta relación con una Fernanda Aguirre que representa la posibilidad de transgredir, desde la práctica individual, las normas de una organización social.

$\mathrm{Si}$ bien las reflexiones de Tesare nunca giran en torno a los problemas clásicos del marxismo, como el modo de producción, las clases sociales, la abolición del Estado, estos puntos aparecen en los textos que retoma el militante y constituyen la base del marxismo pensado como método científico que sostiene las ideas de tiempo desarrolladas. El Manifiesto comunista, El Estado y la revolución, Lecciones de octubre, La revolución traicionada, todos esos textos tienen algo en común, giran en torno a una conceptualización de las revoluciones obreras, comenzando por la Comuna de París en el primer texto y el análisis de la emergencia y caída de la Revolución Rusa en los últimos. No sabemos si las ausencias en el texto de Tesare corresponden a la selección de Norma, pero lo cierto es que la novela exime al lector de la visión ortodoxa del marxismo, concentrándose en una filosofía de los tiempos y la construcción de una tradición.

En referencia al uso de los conceptos marxistas para el análisis literario, haremos una breve aclaración. En 1906, sobre la cercana primera experiencia rebelde en Rusia, Trotsky publica Resultados y perspectivas, donde afirma que el marxismo no es un método de análisis de textos sino de las relaciones sociales ${ }^{9}$. Alude con esto a algunos teóricos que pretenden justificar sus tesis por medio de la enumeración de citas. En ese libro también se incluye un capítulo («1789-1848-1905») sobre las diferencias y herencias de la Revolución francesa, la Comuna de París y la Revolución rusa según los caracteres de clase de cada una de ellas. Luego, a las puertas de la segunda Revolución Rusa, Lenin redacta El Estado y la revolución, trazando un recorrido por los escritos marxistas más importantes que abordan la historia de las revoluciones. El último capítulo queda inconcluso, la escritura se interrumpe cuando la experiencia revolucionaria de 1917 le exige volver a la acción. En ambos trabajos se hace hincapié en la idea del Estado como instrumento de organización

9 Trotsky, (2006): 172 
de la clase dominante, que debe ser transformado y luego destruido, pero Lenin trabaja sobre textos y Trotsky sobre la experiencia de 1905. Uno usa el marxismo para analizar discursos y lecturas, el otro, principalmente, relaciones sociales, pero ambas cuestiones están indisolublemente asociadas de modo que ninguno puede abstraerse de ellas para configurar la tradición revolucionaria.

En nuestro caso, proponemos discutir el vínculo de un texto literario con las relaciones sociales, considerando, como Giorgi Plejanov, que el marxismo es una concepción de mundo, mientras el materialismo histórico es el conjunto de los problemas y métodos de abordaje de estos en relación a la economía política ${ }^{10}$ y el desarrollo económico en el capitalis$\mathrm{mo}^{11}$.

\section{La revolución como clave de lectura}

Sostendremos, como explicamos arriba, un análisis del modo en que se construye la lectura/escritura en la novela, en relación a la organización social que impone condiciones políticas diversas en cada instancia literaria tanto en Argentina como en México, a partir de la revolución como clave de interpretación.

Las citas y reflexiones de Rubén Tesare dibujan el mapa hermenéutico del relato en la superficie de la historia, y lo hacen a partir de la experiencia de un militante argentino en los 70, víctima de la represión ilegal. Por su parte, las escenas de lectura recorren lugares claves para el México revolucionario, como el Museo de la Revolución y la casa de León Trotsky. En los 90, el país centroamericano es asilo de una exiliada cómplice de la represión, mientras en Argentina, luego de más de una década de gobiernos democráticos, se imponen todo tipo de reconfiguraciones político-ideológicas. Allí se debate la noción de la revolución permanente, que sirve especialmente para leer las formaciones sociales en América Latina, donde perviven elementos de organizaciones coloniales antiguas con modernas relaciones capitalistas.

\footnotetext{
${ }^{10}$ Respecto al desarrollo marxista de la economía política, que se concentra en develar las relaciones sociales burguesas que se esconden tras las categorías de esta disciplina, también parte de descifrar una relación temporal, la de valor de cambio. Este se define en El capital según el tiempo de trabajo socialmente necesario para la producción de la mercancía.

11 Plejanov, (1964): 361.
} 
El eje de este recorrido es el tiempo, porque allí se arraiga la transgresión de Norma, la información que elide en su relato es de orden temporal. Ella dice que Tesare ha sido secuestrado, y narra en detalle el viaje a Laguna Chica, pero no cuenta la simultaneidad de ambos hechos. Las incoherencias temporales motivan el descubrimiento y la vacilación que indica que el desaparecido no puede haber escrito lo que estaba sucediendo en su diario si fue aprehendido esa misma noche. Entonces la «verdad» emerge, los diarios no existen, Norma es una estafadora y entregadora. Todo es descubierto sobre el final de la novela, cuando la lectura ha terminado y Marcelo está dispuesto a hacerse de todo el saber que le había sido negado.

Uno de los puntos centrales en la relectura de Tesare sobre la revolución es la tensión permanente entre lo apabullante y brusco del cambio, y la espera de las condiciones objetivas para el desarrollo de la rebelión. De allí que «El paso del tiempo exige dos tipos de virtud revolucionaria: la paciencia y el poder de decisión» ${ }^{12}$. Esta tensión compendia toda la historia de la lectura en Museo de la revolución, él escucha a la espera del momento de rebelarse contra la seductora narradora, decidido a acceder al libro y al final de la historia, aunque esta incluya una dimensión delictiva. Una dinámica de velocidades también define la novela: mientras se dispone un lento recorrido por los textos del marxismo, se precipita un panorama que unifica la lectura de las revoluciones que atraviesan la historia, la última dictadura argentina y el menemismo.

Sin embargo, la primera imagen temporal es la del relámpago, el estallido que marca la etapa inicial de la revolución. Relacionamos esto con la idea de Walter Benjamin en «Sobre el concepto de historia» cuando reclama que un analista-materialista histórico, debe «retener» un recuerdo del instante de peligro: «Al materialismo histórico le toca retener una imagen del pasado como la que imprevistamente se presenta al sujeto histórico en el instante mismo del peligro» ${ }^{13}$. Ante el peligro o la amenaza de la apropiación del pasado por parte de la clase dominante, la función del historiador es arrancar, sustraer, esta tradición del avasallamiento del poder. En este sentido, el regreso a la democracia en Argentina está marcado con la apropiación de la historia por los vencedores, cuestión representada por las leyes de Punto final y Obediencia debida. Entonces es importante retomar la tradición de lectura de un militante

12 Kohan, (2012): 175.

${ }^{13}$ Benjamin, (2012): 170. 
de los 70, tan lejana en el continumm del tiempo histórico que ha de romperse mediante el rescate del pasado.

Para Benjamin, las revoluciones hacen «saltar» el tiempo de la historia en el instante de acción de las clases rebeldes. En este sentido, la Revolución impone un nuevo calendario, el día que comienza es el día en que el tiempo se acelera y no puede medirse con los relojes -de allí la anécdota sobre la lucha en París, donde los rebeldes disparan a los relojes de las torres-. El tiempo se acelera, pero también se detiene en una imagen eterna del pasado que se recogerá como día de rememoración que siempre vuelve ${ }^{14}$. En los escritos de Tesare parece calcarse este reclamo por la transformación de la dimensión temporal, «[...] el tiempo es parte de lo que ha de ser revolucionado. Después de la revolución, el tiempo ya no vuelve a ser lo que era» ${ }^{15}$.

Esto viene a colación del comentario de Tesare en torno el Manifiesto comunista, donde aparece la imagen del estallido. No se repiten pasajes clásicos de dicho texto canónico para los teóricos materialistas como la definición del Estado como administrador de los negocios de la burguesía $^{16}$, la necesidad de abolir la propiedad privada sostenida a costa de la privación de la inmensa mayoría ${ }^{17}$, las ideas como producto de las relaciones de producción burguesas ${ }^{18}$, las medidas a poner en práctica por el proletariado al conquistar el poder ${ }^{19}$, etc.- pero se supone su conocimiento cuando se lo caracteriza como «manual de presagios». El materialista histórico, en los manuscritos de Tesare, es el que puede prever el futuro mediante la utilización del método científico del marxismo, como han logrado hacerlo Marx y Engels en el Manifiesto comunista, Lenin y Trotsky en sus escritos.

Por su parte, cuando se habla de El Estado y la Revolución, no hay casi menciones a la noción de Estado y su carácter de clase, como órgano de dominación y opresión ${ }^{20}$ que impide la conciliación de contradicciones, ni a la necesidad de su supresión violenta por medio de la revolución. Lenin recoge allí el análisis de las experiencias revolucionarias consignadas en el Manifiesto comunista, La guerra civil en Francia y El diecio-

\footnotetext{
${ }^{14}$ CFR. Benjamin, (2012): 178-179.

15 Kohan, (2012): 39.

${ }^{16}$ Marx-Engels, (1998): 17.

${ }^{17}$ Marx-Engels, (1998): 50.

${ }^{18}$ Marx-Engels, (1998): 52.

${ }^{19}$ Marx-Engels, (1998): 62-63 .

${ }^{20}$ Lenin, (2013b): 128.
} 
cho Brumario, para establecer la necesidad de destrucción del Estado ${ }^{21}$. Relatar esta experiencia en base al análisis de los textos de Marx y Engels tiene como objetivo para Lenin leer la Revolución de 1917 en el marco de esta tradición. Pero Tesare sólo postula a Lenin como un «sabio de las cronologías», que maneja la espera y la urgencia de los períodos revolucionarios.

Si la Revolución rusa sigue la obra de la Comuna, confirmando el análisis histórico de los autores del Manifiesto comunista, es porque el socialismo científico implica la anticipación, mediante el examen de las leyes que rigen el desarrollo la historia, de lo que sucederá en el futuro. En esta tensión se define el materialista histórico: entre la preponderancia del presente absoluto que es expresión de un correlato del futuro y la construcción de una tradición de los vencidos a partir de esta explosión, que incluya la posibilidad de prever acontecimientos venideros.

Los escritos de Trotsky tienen una preponderante presencia en la narración, quizás por la cercanía temporal, o por la proximidad espacial con la última vivienda del exiliado en México. La casa del líder ruso en Coyoacán se visita dos veces en la novela, destacando primero la muerte, la soledad y el silencio y luego convirtiéndose en escena de la última lectura de Norma Rossi. En la primera visita, la bandera de la Unión Socialista de Repúblicas Soviéticas marca el fin de la década anterior, signada por la muerte de las ideologías: «ahora se trata de una doble escena de extinción: en la tumba y en la insignia hay que ver, por dos veces, los restos de un difunto» ${ }^{22}$. En la segunda, se constituye un homenaje al revolucionario caído a partir de la lectura de las notas de otro revolucionario derrotado. Todo se superpone y se vuelve exceso en la figura del último líder ruso, el pasado que se asimila como legado marxista, el futuro habitado por figuras de la anticipación y la revolución como trastrocamiento temporal.

El Manifiesto comunista, símbolo de la correcta previsión histórica, vuelve a recuperarse en los escritos de Trotsky que reafirman su vigencia en 1937. También la figura de Lenin, quien penetra con su pensamiento en las coordenadas del futuro ${ }^{23}$. El concepto de revolución permanente

\footnotetext{
${ }^{21}$ Esta declaración viene a discutir la interpretación imperante de estos textos, que sostiene la futura extinción del Estado una vez que el proletariado tome el poder. Se da en el marco de un debate con la II Internacional kautskista.

${ }^{22}$ Kohan, (2012): 70.

${ }^{23}$ Kohan, (2012): 132.
} 
es el que domina la reinterpretación temporal del texto, mediante la imagen de un futuro que está en el pasado y una rebelión que es estallido y salto temporal, superposición de instancias históricas.

Esto último tiene mayor sentido considerando la situación de $\mathrm{Ru}$ sia, territorio dominado por el zarismo que con escasísimo desarrollo del capitalismo se propone emprender una revolución socialista. Ya lo afirma Lenin del siguiente modo: «El marxismo ha roto irrevocablemente con los desvaríos de los populistas y anarquistas, según los cuales Rusia, por ejemplo, podría evitar el desarrollo capitalista, sortear el capitalismo o pasarlo por alto por algún medio que no sea el de la lucha de clases en el terreno y dentro de los límites de ese mismo capitalismo» ${ }^{24}$. Las supervivencias de distintos regímenes garantizan a la burguesía que la revolución no llegue hasta las últimas consecuencias, según el líder ruso.

Para Terry Eagleton tanto Benjamin como Trotsky, ambos intelectuales judíos exiliados, apuntan en sus teorías a la construcción de un discurso histórico no homogéneo, sólo que uno lo trabaja cruzando mesianismo con revolución y el otro como estrategia política: «al asumir el liderazgo de la revolución democrático-burguesa en alianza hegemónica con otras clases y grupos subordinados, el proletariado libera la dinámica que llevará la revolución más allá de sí misma hasta resultar en el poder de los trabajadores $»^{25}$. Las jerarquías se subvierten para dar paso a la rebelión del estrato más débil en la organización mundial, provocando la crisis imperialista. De allí que el Ángelus Novus descrito por Benjamin a partir de un cuadro de Paul Klee se transforme en el ángel de la historia, que se aleja con terror con la mirada vuelta hacia el pasado, la Rusia zarista, en medio de una tempestad que violentamente lo lleva al futuro, la revolución socialista.

\section{Literatura y revolución}

Peinar la historia «a contrapelo» supone para Benjamin apropiarse del pasado que sobreviene súbitamente en el instante revolucionario y así arrancarlo de la hegemonía de las clases dominantes. Por eso escritura y revolución se cruzan en la posibilidad de asir el instante. Si la revo-

\footnotetext{
${ }^{24}$ Lenin, (2013a): 243.

${ }^{25}$ Eagleton, (2012): 266.
} 
lución es puro presente, capacidad de leer la oportunidad en el momento en que los tiempos se aceleran, y el futuro depende de este aprovechamiento por única vez: «También la escritura, al igual que la acción política, tiene que ser capaz de atrapar la fugacidad de ese presente ${ }^{26}$. Capturar la fugacidad del instante de peligro es fundamental para narrar la Historia pero también para narrar una historia, en términos de Benjamin, apoderarse de un recuerdo que «relampaguea en el instante de peligro» ${ }^{27}$.

Ya mencionamos la tensión entre acción y escritura que aparece al final de El estado y la revolución en cuanto al capítulo que relataría la experiencia de la Revolución de 1905 y 1917 en Rusia. La crisis interrumpe la escritura, y entonces el líder encuentra «más agradable y provechoso vivir «la experiencia de la revolución» que escribir sobre ella» ${ }^{28}$. Luego se escribirá sobre las tareas del proletariado, pero en este texto de las tradiciones revolucionarias no se puede insertar la experiencia reciente porque esta es muy cercana, y aún se está «viviendo», 'esta paradoja no cruza también a Tesare que puede reescribir los textos tradicionales del marxismo pero no dar cuenta de su experiencia militante?

Todo el problema en la novela parece erigirse en torno a la lectura y escritura. La primera no cesa de evadir la necesidad informativa del editor, la segunda presenta un método de producción de textos propios a partir de los ajenos, sin poder dar cuenta de la experiencia política inmediata. La sospecha se instala en el relato cuando Marcelo destaca que las conclusiones no parecen ser escritas por un militante de los 70: «Las encuentro, cómo te podría decir, demasiado apartadas de la realidad concreta. Sé que son notas de lectura, y nadie más que yo puede entender lo que son las pasiones de un lector» ${ }^{29}$. Los argumentos de Norma aluden a los últimos sucesos políticos en Argentina, donde se ha usado la palabra «revolución» para esconder intereses represivos, teniendo en cuenta tanto la Revolución del 30 como la Argentina y la Libertadora. La expectativa es «reactivar» conciencias políticas apagadas, combatir el escepticismo impulsado por el cambio de las ideologías o las ideologías del cambio. En una etapa histórica cruzada por «el desgano o la mezquindad del proyecto individual» ${ }^{30}$ una «disposición social» se vuelve excepcional.

\footnotetext{
${ }^{26}$ Kohan, (2012): 175.

27 Benjamin, (2012): 170.

${ }^{28}$ Lenin, (2013b): 210 .

${ }^{29}$ Kohan, (2012):141.

${ }^{30}$ Kohan (2012): 64.
} 
Mientras una larga reflexión de Norma sobre las lecturas de la época pretende funcionar como hipótesis sobre la identidad dividida entre el lector y el militante, la conclusión que se impone es que además de hacer la revolución, Tesare quería pensarla y escribirla ${ }^{31}$. Pero la dinámica de semantización no se separa de lo concreto de las relaciones sociales, pues la presencia de lo criminal, el robo del texto y el secuestro del autor, aporta el nudo de las condiciones de producción extra-textuales. Norma Rossi se apodera de la historia, la memoriosa exiliada junta dos tiempos narrados sin solución de continuidad ${ }^{32}$ mientras un receptor de su ficción va tomando fuerza hasta convertirse en un lector crítico que inquiere, participa en la narración y sospecha hasta descubrir su origen ilegítimo. Hay una dinámica de la relación en la que domina el engaño y la estafa, en que la relatora administra información pero deja huellas de la mentira -la inexistencia del diario- y de su crimen -la complicidad en el secuestro-. Mientras, el lector de Kohan también se enfrenta a la estafa y sospecha sobre el saber de Norma, identifica la operación crítica de interpretación propia con la de Marcelo, pero a la vez, debe sospechar de este narrador en primera instancia.

Al final, la superposición de los tiempos, la transgresión de las cronologías no solo es un modo de relatar, sino que se convierte en el modo de leer, ligado a las normas del policial: «Voy a leer el final, como si fuese un lector de policiales, que, capturado por la intriga, no puede soportar más no saber cómo termina la historia y decide saltear todo lo que falta para llegar directamente al desenlace» ${ }^{33}$. Ese desenlace plantea la contradicción entre interpretación y realidad, entre escritura y acción, que finalmente no es tal. En Dos tácticas de la socialdemocracia en la revolución democrática (Lenin, 1905) se señala que las revoluciones impulsan un período de creatividad, son días de júbilo en que cualquier milagro puede suceder, donde las masas son creadoras activas de nuevos regímenes sociales ${ }^{34}$ ¿No resuena esto bastante cercano a la posibilidad de crea-

\footnotetext{
${ }^{31}$ Kohan, (2012): 143.

32 En ocasiones no hay una marca de cambio en la enunciación, sino que las historias se imbrican de manera que se produce un efecto de continuidad entre el recorrido de la ciudad de México por Norma y Marcelo y la historia de Tesare y Fernanda (p. 97), mientras Norma camina con naturalidad por Polanco, se inserta en el relato la imagen de los pies de Fernanda Aguirre.

${ }^{33}$ Kohan, (2012): 236.

${ }^{34}$ Lenin, (2013a): 286.
} 
ción que experimentamos mediante la literatura, en la que mundos nuevos pueden crearse a partir del lenguaje?

La historia de Tesare no será publicada, pero Marcelo la usará para escribir un relato propio. La tradición revolucionaria se seguirá relatando en una imagen de la globalidad apropiada por los vencidos, en palabras de Eagleton: «Sólo cuando este «texto» esté escrito por completo, podrán ser contados apropiadamente los relatos nacionales que lo componen» ${ }^{35}$. Finalmente La revolución permanente tiene como cara opuesta, según Tesare La revolución traicionada, si no puede pensarse la revolución después de la revolución «Si todo este dispositivo, con su respectivo diseño de temporalidades fracasa o se pierde, la revolución permanente pasa a ser revolución traicionada ${ }^{36}$. Entre estas dos perspectivas se define el relato, permanencia de la lectura que superpone distintos tiempos históricos y traición de los apropiadores de esta memoria que anulan la voz de los vencidos mediante la violencia.

\section{El relato de la verdad y la traición}

El procedimiento discusivo que propone el armado de un texto a partir de la apropiación de otro/s, y de la ficcionalización del proceso de la escritura es el de la semiosis delictiva ${ }^{37}$-entendida como los modos de apropiación «ilegítima» de textos ajenos que no son otra cosa que las condiciones de producción penetradas por las relaciones de propiedad dominantes-. Las normas del género policial se leen así en clave literaria, a partir de esto podemos indicar alguna línea de lectura en común con lo que esboza Ricardo Piglia en «Nombre falso». Hay allí un texto inédito en cuestión, al igual que en Museo de la Revolución, pero el mecanismo del dinero que determina el relato de Piglia es reemplazado por el dispositivo de seducción/traición ${ }^{38}$ de la narradora cómplice de un cri-

\footnotetext{
35 Eagleton, (2012): 267.

${ }^{36}$ Kohan, (2012): 153.

${ }^{37}$ Sobre esta temática discurrimos en nuestro libro Dinero y delito. La tradición materialista en la lectura/escritura pigliana del policial. Allí trabajamos los textos de Pliglia «La loca y el relato del crimen», Plata quemada» y «Nombre falso», realizando un recorrido sobre los modos en que éstos dialogan con los principales conceptos del materialismo.

${ }^{38}$ Esta cuestión no es ajena a las normas de un género de masas como el policial, según plantea Ana María Amar Sánchez en su libro, Juegos de seducción y traición (2000). Allí se aborda la seducción a que se somete un lector ante un relato de género y la traición que perpetra el discurso cuando transgrede esas normas.
} 
men de Estado, que ha robado un manuscrito de su víctima en el texto de Kohan.

1975 es el año en que un grupo de tareas secuestra al protagonista de la novela de Kohan. En el mismo año, Piglia escribe el conjunto de relatos que dan forma al libro Nombre falso ${ }^{39}$, donde figura la novela corta homónima. También se refiere allí la búsqueda de un manuscrito inédito por parte de un engañado editor. Sólo que en este caso el editor es el personaje Ricardo Piglia y el escritor es Roberto Arlt, lo que configura un mapa de citas no declaradas que reestructuran las tradiciones de la literatura argentina y universal. El cuento «Las tinieblas», de Leonid Andrèiev, es reescrito en clave arltiana bajo el nombre de «Luba», e incluido como apéndice en la nowvelle pigliana. Es decir, hay un robo ficcional -que se narra- y metaliterario, que sirve para hablar del modo en que la literatura trabaja con las condiciones de producción que incluyen los textos y las relaciones de propiedad entre éstos.

En este caso, quisiéramos llamar la atención sobre dos figuras femeninas que aparecen en estos discursos literarios y que configuran las claves de su lectura. La primera es la de la mendiga, que se retoma en «Nombre falso» al modo de una intertextualidad con la propia obra (es el personaje que permite a Renzi descifrar el misterioso asesinato en «La loca y el relato del crimen») y en Museo de la Revolución, como amenaza e indicio de la represión parapolicial. En el primer texto, el personaje de las notas arltianas, Rinaldi -que está planeando el envenenamiento de su mujer- la encuentra en una estación de subte y le da dinero, luego la mujer es la que advierte a Lissette de su próxima muerte por envenenamiento, a la manera de una Casandra pobre y harapienta cuya verdad no es escuchada. En el segundo, la mendiga que vaga por la Estación terminal de colectivos en un pueblo cordobés insulta al revolucionario, lo escupe y le pide dinero pero es reprimida por un «policía de civil» que defiende al «señor» turista. Su presencia se configura así como un signo de advertencia, una vez más deslegitimada, ignorada por el avisado, y como primer indicio de la existencia de grupos de tareas civiles que operan luego en el secuestro del militante.

Aún más clave es la figura de Norma, que se vale de su cuerpo para interceptar a Tesare, y la de Luba, la prostituta que cuestiona la pureza del anarquista sin llegar a ponerla en crisis. En este caso, si bien en Museo de la Revolución no se la asocia directamente a la figura de la

${ }^{39}$ Piglia, (2014):11. 
prostituta, se multiplican indicios que colocan a la exiliada argentina en espacios como el bar de Polanco, donde se ofrecen mujeres. Mientras Norma delata a Tesare en la novela de Kohan, Luba elige escapar con el anarquista en el texto de Piglia. Ambas trazan configuraciones que redefinen la posibilidad de traición como respuesta particular a las contradicciones sociales que determinan a los personajes. El militante puro que sacrifica sus intereses individuales en pos de la verdad histórica pone en crisis a las mujeres poseedoras de una evidencia peligrosa. Así increpa Luba a las prostitutas que recuerdan que una vez fueron honradas: «Ustedes han perdido el honor, mientras que él lo ha sacrificado» ${ }^{40}$. La pureza moral del anarquista que en dicho relato elude la relación sexual contrasta con la prostituida Luba, rescatada al final en el gesto redentor de la huida conjunta.

Con Tesare sucede al revés, pero el resultado sigue siendo la traición como respuesta individual ante las contradicciones sociales. El revolucionario opera en la clandestinidad, pero no se esconde en un prostíbulo para escaparse con una desdichada aliada del inframundo, sino que suspende su sacrificio individual para acostarse con Fernanda Aguirre. Esa transgresión a la moral revolucionaria es la que lo pierde: «Tesare quiere salirse de esa noche de espera, quiere salirse de Laguna Chica, del bolso, de los compañeros, quiere salirse de la comisión de control y de la limpidez ideológica, quiere salirse de su propio sentido de la obediencia, de su lealtad y su falta de lealtad $»^{41}$. Su conducta es la del $«$ converso ${ }^{42}$ y en el trato desenfadado, enardecido, se lee el desacato a la norma de la organización y al estereotipo del militante incorruptible.

Tanto en el anarquista de «Luba» como en el revolucionario de Kohan se resignifica la vanidad de una supuesta superioridad moral que tensiona con los personajes femeninos. Para dar cuenta de ello, Norma Rossi revela en parte su secreta intervención en la historia «Yo podría referir la irritante certeza que Tesare tenía de estar haciendo gozar a Fernanda Aguirre, completamente convencido del funcionamiento de esas audacias presuntas» ${ }^{43}$. El efecto producido por la conjunción de personajes opuestos, guiados unos por el presuntuoso interés de la trasforma-

\footnotetext{
${ }^{40}$ Piglia, (2014): 177.

${ }^{41}$ Kohan, (2012): 144-145.

${ }^{42}$ La revisión de la figura del revolucionario, que marca fuertemente los 60 y 70, implica en la novela de Kohan una transgresión a la rígida moral militante, de aquel que ha comenzado a modificar su ideología, al menos en la exigida conducta ética.

${ }^{43}$ Kohan, (2012): 146.
} 
ción revolucionaria en contraste con la «bajeza» de quien vive a partir del intercambio sexual es el universo común que en Piglia se lee como el proyecto de Arlt, «Un tema: el hombre puro y la mala mujer en una situación extrema, Encerrados: ver cómo cambian, se transforman ${ }^{44}$.

En esa situación clandestina se dibujan las ilegalidades textuales que cruzan los relatos, los robos, los secuestros, la violencia represiva. La prestidigitadora Norma distrae a Marcelo con un espectáculo de seducción lectora para ocultar su crimen. Aunque nunca se relata el porqué de la complicidad de Norma, sí queda estampada su perspectiva: «Ahora no se sabe qué fue de él. Ese desenlace, que ni siquiera es el de la muerte, sino el de la incógnita, puede que lo arrastre a la apariencia de lo compacto ${ }^{45}$. Este es uno de los mayores indicios respecto de la traición de Norma, más allá de los textos que oculta o las incongruencias temporales de su historia, e incluso de los momentos en que su perspectiva se abre. El escritor es un falsificador y un ladrón en Piglia, al igual que la narradora es una estafadora, ladrona y criminal en Kohan, y el lector es un crítico que en «Nombre falso» debe descubrir el secreto de la apropiación de los textos.

Mientras que en Kohan el editor-lector-escritor descifra la confiscación ilegal del manuscrito y el secuestro de Tesare, pero al modo de una repetición infinita, vuelve a «robar» el cuaderno para escribir su propio relato, el que leemos, narrado en primera persona desde su perspectiva.

Como en las notas de Arlt que el personaje Piglia reproduce en su relato, en las que el escritor determina: «Creo que a nosotros nos ha tocado la misión de asistir al crepúsculo de la piedad y que no nos queda otro remedio que escribir deshechos de furia para no salir a la calle a tirar bombas o a instalar prostíbulos» ${ }^{46}$, Marcelo se sienta a escribir perdiéndose la caída del atardecer mexicano, capturando y relatando la historia repetida de los tiempos revolucionarios, desde la voz de los vencidos.

\footnotetext{
${ }^{44}$ Piglia, (2014): 123.

${ }^{45}$ Kohan, (2012): 143.

${ }^{46}$ Piglia, (2014): 125.
} 


\section{Bibliografía}

AMAR SÁNCHEZ, Ana María (2000) Juegos de seducción y traición. Literatura y cultura de masas. Buenos Aires: Beatriz Viterbo Editora.

BENJAMIN, Walter, (2012), «Sobre el concepto de historia». Escritos políticos. Madrid: Abada editores. 167-181

EAGLETON, Terry (2012) Walter Benjamin o hacia una critica revolucionaria. Madrid: Cátedra.

KOHAN, Martín, (2012), Museo de la Revolución. Buenos Aires: Debolsillo.

LENIN, (2013a), «Dos tácticas de la socialdemocracia en la revolución democrática». Obras selectas. 220-304

LENIN, (2013b), «El Estado y la revolución». Obras selectas. 123-210

MARX, Karl, Friedrich ENGELS (1998), Manifiesto Comunista. Barcelona: Debate.

MARX, Karl (2014), El capital. Critica de la economía politica. Tomo I/ Vol. I Libro Primero. El proceso de producción del capital. Buenos Aires: Siglo veintiuno editores.

PIGLIA, Ricardo, (2014), Nombre falso. Buenos Aires: Debolsillo.

PLEJANOV, Giorgi (1964), «Las cuestiones fundamentales del marxismo». Obras escogidas. Buenos Aires: Quetzal. 359-426

TROTSKY, León (1971) Resultados y perspectivas. Las fuerzas motrices de la revolución. París: Ruedo Ibérico, 1971.

TROTSKY, León (2013) Escritos latinoamericanos en México. Buenos Aires: Ediciones IPS. 